\title{
REPORT ON THE MAGNETIC OBSERVATIONS MADE AT THE UNIVERSITY OF GRONINGEN DURING THE TOTAL SOLAR ECLIPSE OF MAY 17, 18, I90I.
}

\author{
By Professor W. Haga.
}

At the request of Dr. van Rijckevorsel, I have made in the laboratory of the University of Groningen, during the night between I7-I 8 May, observations of the variations of declinations and of the horizontal intensity.

The laboratory is quite free from iron, and lies in a garden far from the railway, canals, and frequented streets. In Groningen there are no electric car lines nor electric plants, hence we are undisturbed by stray or "vagabundirende" currents.

The variations of declination were observed by means of a unifilar magnetometer of Kohlrausch; scale and telescope were at a distance of $429.7 \mathrm{c}$. $\mathrm{m}$., so that a change in the direction of the magnet of $\mathrm{I}^{\prime}$ gives a displacement of the image of the scale of $2.5^{\mathrm{mm}}$.

The telescope had an aperture of $40^{\mathrm{mm}}$, a focal length of $45^{\circ \mathrm{mm}}$, and a magnifying power of 55 times; the readings were accurate, at least to $0 . \mathrm{I}^{\mathrm{mm}}$, now and then $0.05^{\mathrm{mm}}$ being estimated.

For obtaining the variations of the horizontal intensity we made use of the variometer of Kohlrausch with the four little magnets; the distance of the scale had been chosen as $374.9 \mathrm{c}$. m., so that, with the value of $\phi=20^{\circ} 33^{\prime}$ a displacement of $x^{\mathrm{mm}}$ of the image of the scale corresponds to a variation of $0.00005 H$. The telescope was similar to that used with the magnetometer.

The variometer was placed in the basement (sous-terrain) where the temperature is very constant; the difference in temperature during the time of observation did not surpass $0 .{ }^{\circ} \mathrm{r}$ c. Messrs. G. van Dijk and J. Kunst, students, candidates in science, assisted me in making the observations. They are much accustomed in this sort of work, being more than a year occupied with an absolute determination of the electrochemical equivalent of silver.

From $\mathrm{I}^{\mathrm{h}} 2 \mathrm{O}^{\mathrm{m}}-2 \mathrm{I}^{\mathrm{h}}$, May I7, Greenwich mean astronomical time, a reading was made every minute. On the curves forwarded every dot represents a reading: $\mathrm{I}^{\mathrm{mm}}$ of the ordinate $=0 . \mathrm{I}^{\mathrm{mm}}$ of the scale-reading. The numbers on the left side belong to curve I (intensity), those on the right to curve II (declination); hence, for instance, at $16^{\mathrm{h}}$ o $5^{\mathrm{m}}$ the reading of the variometer was 416.4 ; of the magnetometer 404.0.

Groningen lies in latitude $53^{\circ} 13^{\prime} 12^{\prime \prime} \mathrm{N}$. and in longitude $6^{\circ} 34^{\prime} 17^{\prime \prime}$ East of Greenwich.

I hope that these observations may be of some use for the investigation under consideration. ${ }^{x}$

1 The publication of table of readings must be deferred until next issue.-ED. 